\title{
INFLUENCE OF INORGANIC COMPOUNDS ON THE PROCESS OF PHOTOCATALYSIS OF BIOLOGICALLY ACTIVE COMPOUNDS
}

\author{
Edyta Kudlek', Mariusz Dudziak', Jolanta Bohdziewicz'1, Gabriela Kamińska' \\ 1 Silesian University of Technology, Institute of Water and Wastewater Engineering, Konarskiego 18a, 44-100 \\ Gliwice, Poland, e-mail: edyta.kudlek@polsl.pl
}

Received: 2017.04.30

Accepted: 2017.05.31 Published: 2017.07.01

\begin{abstract}
Constant increase in concentration of organic micropollutants in the water environment influences the development of methods for their effective elimination from various matrices released into aquatic ecosystems. One of widely described in literature processes for the decomposition of hardly-biodegradable pollutants is the process of heterogeneous photocatalysis. The paper presents the influence of inorganic substances on the decomposition of polycyclic aromatic hydrocarbons (anthracene and benzo[a]pyrene), industrial admixtures - octylphenol and pharmaceutical compounds - diclofenac in the photocatalysis process conducted in the presence of $\mathrm{TiO}_{2}$. It has been shown that the presence of $\mathrm{Cl}^{-}$ions did not affect the photochemical reaction of the micropollutant decomposition. Whereas, the presence of $\mathrm{CO}_{3}^{2-}, \mathrm{SO}_{4}^{2-}$ and $\mathrm{HPO}_{4}^{2-}$ ions inhibited the decolonization of octylphenol and diclofenac, while the degradation efficiency of anthracene and benzo[a]pyrene was reduced only by the presence of $\mathrm{CO}_{3}^{2-}$ and $\mathrm{HCO}_{3}^{-}$anions. The photooxidation of micropollutants in solutions containing $\mathrm{Al}^{3+}$ oraz $\mathrm{Fe}^{3+}$ cations proceeded with a much lower efficiency than that for solution without inorganic compounds. The analysis of the kinetics of the photocatalytic decomposition of selected micropollutants show a decrease in the reaction rate constant and an increase in their half-life due to the blocking of theactive semiconductor centers by inorganic compounds. In addition,the toxicological analysis inducated the generation of micropollutant oxidation by-products, which aggravate the quality of treated aqueous solutions.
\end{abstract}

Keywords: water environment, organic micropollutants, photocatalysis, cations, anions

\section{INTRODUCTION}

Water is a valuable resource, whose physical and chemical composition depends strictly on human activity. Research undertaken in order to determine the degree of anthropogenic pollution of water environment indicates the presence of various micropollutant groups in surface water, groundwater and even drinking water sources [ $\mathrm{Li}$ et al. 2015, Ternes et al. 2015]. The most of the municipal WWTPs are not designed to completely eliminate organic micropollutants, making the treated effluent a major source of that kind of pollution [Tijani et al. 2013, Morris et al. 2017].
Advanced oxidation processes (AOPs), such as photolysis or photocatalysis are conceptually based on the production of highly reactive oxidizing species $\left(\mathrm{HO}^{\circ}, \mathrm{O}_{2}^{-}, \mathrm{HO}_{2}{ }^{\circ}\right.$ ) are able to oxidize unselectively organic pollutants and can be used as an effective post-treatment of a biological process [Giannakis et al. 2015, Moreira et al. 2016]. One of the most important features, deciding on the decomposition of compounds during the photocatalysis process, is the adsorption of micropollutants in active centres of the applied catalyst. The process of micropollutants adsorption may be hindered by the presence of inorganic compounds such as $\mathrm{Cl}^{-}, \mathrm{NO}_{3}^{-}$and $\mathrm{SO}_{4}^{2-}$ anions, that are 
able to block active centres on the catalyst surface [Chládková et al. 2015]. On the other hand, composite catalysts formed from $\mathrm{TiO}_{2}$ nanoparticles and some inorganic compounds may have a higher photocatalytic activity than conventional semiconductors [Zhang et al. 2016]. The effectiveness of the process depends therefore also on the physicochemical composition of the treated solution. It is necessary to determine which compounds support the micropollutant oxidation process and which act as decomposition inhibitors.

This paper describes the efficiency of removal of different micropollutants identified in the aquatic environment, i.e., diclofenac, octylphenol, anthracene and benzo[a]pyrene, from water suspensions in the process of heterogenic photocatalysis with the presence of selected inorganic compounds. The photochemical oxidation was conducted in the presence of titanium dioxide as a catalyst of this process. The LangmuirHisherwood equation allowed the description of the kinetics of the process. The efficiency of the process was assessed on the basis of the decrease in concentration of micropollutants measured by the use of high-performance liquid chromatography preceded by solid phase extraction.

\section{MATERIALS AND METHODS}

The research was carried out by using water solutions of selected micropollutants: diclofenac (DCF), octylphenol (OP), anthracene (ANT) and benzo[a]pyrene $(\mathrm{BaP})$ purchased from SigmaAldrich (Poznań, Poland). The basic characteristic of micropollutants was shown in Table 1. The concentration of tested compounds in the prepared water solutions was established at $500 \mu \mathrm{g} / \mathrm{L}$. The influence of inorganic ions on the efficiency of photocatalytic oxidation of micropollutants was determined by the addition of $1 \mathrm{~mol} / \mathrm{L}$ inorganic salts, i.e., $\mathrm{NaCl}, \mathrm{Na}_{2} \mathrm{SO}_{4}, \mathrm{NaHCO}_{3}, \mathrm{Na}_{2} \mathrm{HPO}_{4}$ and $\mathrm{AlCl}_{3}, \mathrm{FeCl}_{3}$ to the water solutions.

The process of heterogenic photocatalysis was conducted in a laboratory glass reactor with a volume of $700 \mathrm{~mL}$ by Heraeus (Hanau, Germany). The reactor was equipped with a medium-pressure mercury vapour UV lamp $(150 \mathrm{~W})$, which emanated radiation with a wavelength $\lambda_{\text {exc }}$ range from 313 to $578 \mathrm{~nm}$. The lamp was placed in a cooling jacket, which enabled to keep a constant temperature of the conducted process that did not exceed $20 \pm 1{ }^{\circ} \mathrm{C}$. The reactor was placed on a magnetic stirrer and connected to an aeration pump of capacity of $4 \mathrm{~L}$ air per minute to oxidate the system. $\mathrm{TiO}_{2}$ was applied as a catalyst of the photocatalysis process and it was purchased from Evonik Degussa GmbH (Hanau, Germany) as a mixture of anatase and rutile in the ratio 75:25. The dose of catalyst applied to the reaction mixture reached the level of $100 \mathrm{mg} / \mathrm{L}$. To ensured the adsorption of micropollutants on the surface of the catalyst the water solutions were mixing with the $\mathrm{TiO}_{2}$ particles for $15 \mathrm{~min}$ before UV irradiation. The separation of catalyst from the post-reaction mixture was conducted by the use of a filtration set equipped with glass filters of $0.45 \mu \mathrm{m}$ pore sizes by Merck Milipore (Darmstadt, Germany), with vacuum pump by AGA Labor (Warsaw, Poland).

The kinetics of the photochemical process was estimated with the Langmuir-Hinsherwood equation, as a correlation between the micropollutant concentration in the solutions and the time of UV irradiation Eq. (1). With the assumption, that the decomposition process of the investigated compound becomes a pseudo-first order reaction, the reaction rate constant $k$ may be established as a linear regression slope Eq. (2), where $K$ is an equilibrium constant of the micropollutant adsorption on the $\mathrm{TiO}_{2}$ surface, whereas $C_{0}, C_{t}$ is

Table 1. Physicochemical characteristic of studied organic micropollutants

\begin{tabular}{|c|c|c|c|c|}
\hline Compound group & Pharmaceutical & Industrial admixture & \multicolumn{2}{|c|}{ Polycyclic aromatic hydrocarbons } \\
\hline Micropollutant & Diclofenak sodium salt & Octylphenol & Anthracene & Benzo[a]pyrene \\
\hline \multicolumn{5}{|l|}{ Structural formula } \\
\hline Molecular formula & $\mathrm{C}_{14} \mathrm{H}_{10} \mathrm{Cl}_{2} \mathrm{NNaO}_{2}$ & $\mathrm{C}_{14} \mathrm{H}_{22} \mathrm{O}$ & $\mathrm{C}_{14} \mathrm{H}_{10}$ & $\mathrm{C}_{20} \mathrm{H}_{12}$ \\
\hline CAS No & $15307-79-6$ & $1806-26-4$ & $120-12-7$ & $50-32-8$ \\
\hline Molecular weight, $\mathrm{g} / \mathrm{mol}$ & 318.13 & 206.32 & 178.23 & 252.31 \\
\hline Solubility in water, $\mathrm{mg} / \mathrm{L}$ & 50 & 7.0 & 0.044 & 0.00147 \\
\hline $\log K_{o w}$ & 4.51 & 4.80 & 4.45 & 5.97 \\
\hline
\end{tabular}


the compound concentration in the water solution before the irradiation process $(t=0)$ and after a given time $t$. The half life $t_{\frac{1}{2}}$ of the compound was identify on the basis of the Eq.(3).

$$
\begin{gathered}
r=\frac{d C}{d t}=k\left(\frac{K C}{1+K C}\right) \\
\ln \left(\frac{C_{t}}{C_{0}}\right)=-k t \\
t_{\frac{1}{2}}=\frac{\ln 2}{k}
\end{gathered}
$$

The concentration of micropollutants before and after the oxidation process was measured by high-performance liquid chromatography HPLC equipped with UV-VIS detector by Varian (Warsaw, Poland). The analytes were separated from water samples with a volume of $20 \mathrm{~mL}(\mathrm{pH}=7)$ with solid phase extraction (SPE) in a single-use columns Supelclean ${ }^{\mathrm{TM}}$ ENVI-18 volume $6 \mathrm{~mL}$ $(1.0 \mathrm{~g})$ by Supelco (Poznań, Poland). Details of column bed preparation, analyte extraction and elution were presented in Kudlek et al. (2017) and Bohdziewicz et al. (2016). The chromatographically identifications of the micropollutants were conducted by the use of Hypersil GOLD column by Thermo Scientific (Warsaw, Poland) of length equal to $25 \mathrm{~cm}$, diameter of $4.6 \mathrm{~mm}$ and granulation of $5 \mu \mathrm{m}$. Detector wavelength $\lambda$ necessary to obtain the required sensitivity was established for DFC and OP at $220 \mathrm{~nm}$ and at 254 $\mathrm{nm}$ for ANT and BaP.

\section{RESULTS AND DISCUSSION}

In the first stage of study the concentration decrease of organic micropollutant water solution with selected anions added as sodium salts was investigated. The obtained results were presented at Figure 1. The presence of inorganic compounds affect on the adsorption process of the investigated organic compounds on the photocatalyst particles. For example, the concentration of DCF decreased in water solution containing $\mathrm{Cl}^{-}$at about $9 \%$ (Fig. 1a, reaction time $0 \mathrm{~min}$ ) while in the presence of $\mathrm{HCO}_{3}^{-}$and $\mathrm{HPO}_{4}^{2-}$ the a)

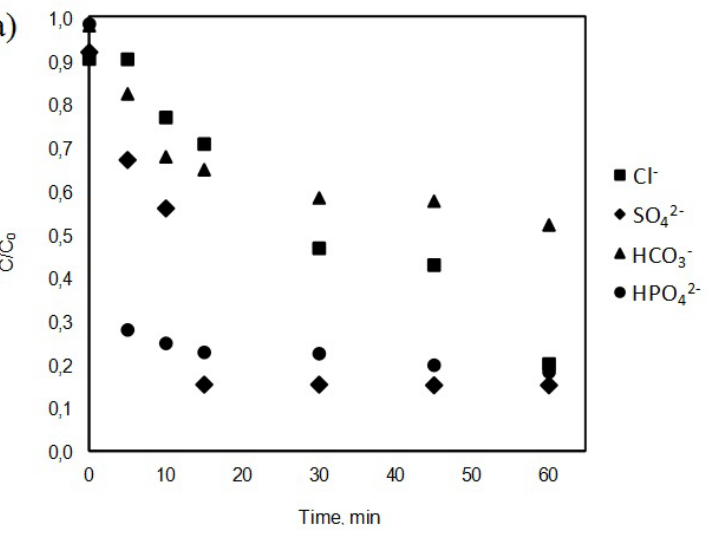

c)

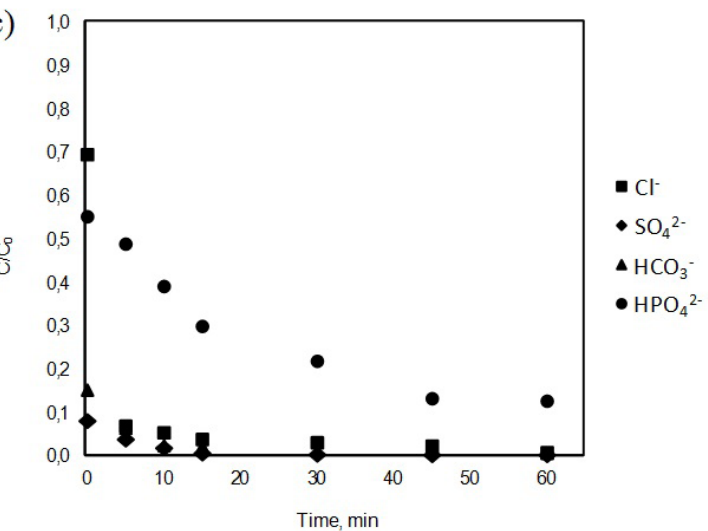

b)

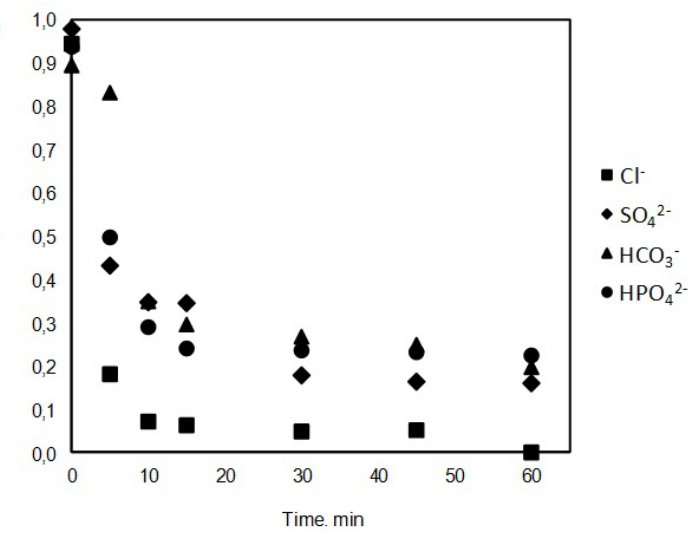

d)

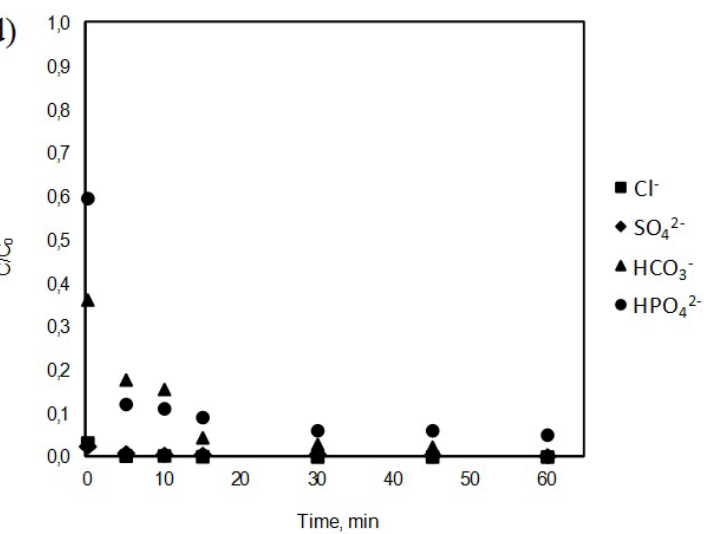

Figure 1. Influence of selected anions on the photocatalytic degradation of (a) DCF; (b) OP, (c) ANT and (d) $\mathrm{BaP}$ present in water solutions 
adsorption on $\mathrm{TiO}_{2}$ nanoparticles allowed only for a $2 \%$ decrease in the concentration of the compound. However, for solutions without inorganic compounds a $20 \%$ reduction in DCF concentration was observed (Fig. 2a). Also in OP and $\mathrm{BaP}$ solutions a negative influence of the tested ions on the degree of adsorption of micropollutants on the surface of the semiconductor was observed. The concentration of $\mathrm{BaP}$ it the presence of $\mathrm{HCO}_{3}{ }^{-}$and $\mathrm{HPO}_{4}{ }^{2-}$ decreased only by 64 and $40 \%$ respectively, and for the solution without the addition of salt the removal degree reached more than $95 \%$. Only in the case of ANT solution a beneficial effect of $\mathrm{SO}_{4}{ }^{2-}$ and $\mathrm{HCO}_{3}{ }^{-}$ions on the adsorption degree of the compound on the $\mathrm{TiO}_{2}$ surface was reported (Fig 1c).

The start of UV irradiation of the reaction mixtures resulted in a gradual increase of the micropollutant removal. The removal degree of DCF after $60 \mathrm{~min}$ of irradiation of solutions containing $\mathrm{Cl}^{-}, \mathrm{SO}_{4}^{2-}, \mathrm{HCO}_{3}^{-}$, and $\mathrm{HPO}_{4}^{2-}$ reached $80 \%, 85 \%, 45 \%$ and $82 \%$ respectively. For OP water solution the highest decrease in the compound concentration exceeding $99 \%$ was observed for reaction mixtures containing $\mathrm{Cl}^{-}$ions (Fig. 1b). Conversely, the lowest reduction in the concentration of this compound, which did not exceed $77 \%$ was observed in solution, which consisted $\mathrm{HPO}_{4}^{2-}$ ions.

The concentration of ANT with the presence of such ions as $\mathrm{Cl}^{-}$and $\mathrm{HPO}_{4}^{2-}$ after $15 \mathrm{~min}$ of photochemical oxidation decreased by $96 \%$ and $70 \%$ respectively (Fig. 1c). Only the presence of $\mathrm{HCO}_{3}^{-}$and $\mathrm{SO}_{4}^{2-}$ did not affect on the decomposition mechanism of that compound and the micropollutant removal rate reached the same level of $98 \%$ as for solutions with no salt. Different correlations were observed in case of $\mathrm{BaP}$ (Fig. 1d). The addition of $\mathrm{HCO}_{3}^{-}$as well as $\mathrm{HPO}_{4}^{2-}$ decreased the efficiency of the process and the obtained removal rates for this compound did not exceed $88 \%$ after 5 min of UV irradiation. In case of $\mathrm{Cl}^{-}$and $\mathrm{SO}_{4}^{2-}$ ions did the removal rate for $\mathrm{BaP}$ reach $99 \%$. The same compound removal degree was also obtained for the solution without the addition of salt (Fig. 2d).

The inhibition of the oxidation of the investigated micropollutants was caused mainly by the blocking of active centers on catalyst surfaces by competitive adsorbed $\mathrm{Cl}^{-}, \mathrm{SO}_{4}^{2-}, \mathrm{HCO}_{3}^{-}$, and $\mathrm{HPO}_{4}^{2-}$ ions. It should be emphasized, that the mechanism of the heterogeneous photocatalysis assumes that the oxidation of micropollutants by reaction with high reactive radicals occurs only when these compounds are adsorbed on the surface of the semiconductor, or are directly in close proximity [Augugliaro et al. 2012]. Therefore, if the presence of some ion group reduces the adsorption degree of organic compounds, it will also affect on the efficiency of the whole process of their photochemical decomposition.

The analysis of the kinetics of the heterogeneous photocatalysis occurring in the presence of $\mathrm{Cl}^{-}, \mathrm{SO}_{4}^{2-}, \mathrm{HCO}_{3}^{-}$, and $\mathrm{HPO}_{4}^{2-}$ ions proved in some cases a significant difference between the rapidity of organic compounds' degradation observed during the first $15 \mathrm{~min}$ of the process and the rapidity of the decomposition reactions observed after the 15 th min of UV radiation (Table 2). For example, the process of DCF decomposition in the solution containing $\mathrm{SO}_{4}^{2-}$ ions runs with a high reaction rate constant within the first 5 min of UV irradiation, and the half-life of the micropollutant reaching $5.4 \mathrm{~min}$, but after the 15 th $\mathrm{min}$ of the process the reaction rate constant significantly decreases and the DCF half-life exceeded $8513 \mathrm{~min}$. Such large difference in the compound half-life was also observed in the case of OP decomposition in the presence of $\mathrm{HPO}_{4}^{2-}$ ions. The OP half-life up to $15 \mathrm{~min}$ of UV irradiation was equal to 9.3 min and then increases to $1395.4 \mathrm{~min}$. A constant value of the reaction rate and the half-life during the whole $60 \mathrm{~min}$ of process running time was observed only for solutions containing DCF in the presence of $\mathrm{Cl}^{-}$ions, ANT with $\mathrm{HPO}_{4}^{2-}$ ions and $\mathrm{BaP}$ with $\mathrm{Cl}^{-}$or $\mathrm{HCO}_{3}^{-}$ions.

These differences of the calculated compound half-life values may result from the formation of oxidation by-products, which were competitive adsorbed on the surface of catalyst or from the blocking of catalyst active centres by inorganic compounds, which leads to the inhibition of the oxidation of investigated parent compounds.

Figure 2 presented the influence of $\mathrm{Al}^{3+}$ and $\mathrm{Fe}^{3+}$ cations on the photochemical decomposition of investigated micropollutants. Both cations applied to the suspensions significantly influenced the adsorption rate of DCF and OP on the catalyst surface. The DCF decrease rate reaching 17\% for $\mathrm{Al}^{3+}$ and $1 \%$ for $\mathrm{Fe}^{3+}$ (Fig. 2a), whereas the OP decrease rate reaching $44 \%$ and $22 \%$ correspondingly (Fig. 2b). In the case of polycyclic aromatic hydrocarbons ANT and BaP adsorption only the presence of $\mathrm{Fe}^{3+}$ inhibited the adsorption of the compound on $\mathrm{TiO}_{2}$ nanoparticles. The concentration of ANT after the sorption process conducted 
Table 2. Half-life of investigated compounds during heterogeneous photocatalysis in the presence of selected anions

\begin{tabular}{|c|c|c|c|c|c|}
\hline Compound & Ions & Reaction Time. min & Reaction Rate Constant k. min $^{-1}$ & $R^{2}$ & Half-Life $t_{1 / 2} \cdot \min$ \\
\hline \multirow{7}{*}{ DCF } & $\mathrm{Cl}$ & $0-60$ & 0.0236 & 0.95 & 30.0 \\
\hline & \multirow{2}{*}{$\mathrm{SO}_{4}^{2-}$} & $0-15$ & 0.1107 & 0.83 & 5.4 \\
\hline & & $15-60$ & 0.0003 & 0.8 & 8513.8 \\
\hline & \multirow{2}{*}{$\mathrm{HCO}_{3}^{-}$} & $0-15$ & 0.0286 & 0.95 & 25.7 \\
\hline & & $15-60$ & 0.0044 & 0.93 & 242.5 \\
\hline & \multirow{2}{*}{$\mathrm{HPO}_{4}^{2-}$} & $0-10$ & 0.1373 & 0.81 & 6.5 \\
\hline & & $10-60$ & 0.0044 & 0.93 & 242.5 \\
\hline \multirow{8}{*}{ OP } & \multirow{2}{*}{$\mathrm{Cl}$} & $0-15$ & 0.1804 & 0.87 & 6.3 \\
\hline & & $15-60$ & 0.0880 & 0.64 & 15.6 \\
\hline & \multirow{2}{*}{$\mathrm{SO}_{4}^{2-}$} & $0-30$ & 0.0489 & 0.85 & 21.4 \\
\hline & & $30-60$ & 0.0036 & 0.89 & 644.6 \\
\hline & \multirow{2}{*}{$\mathrm{HCO}_{3}^{-}$} & $0-15$ & 0.0837 & 0.89 & 8.5 \\
\hline & & $15-60$ & 0.0086 & 0.93 & 204.5 \\
\hline & \multirow{2}{*}{$\mathrm{HPO}_{4}^{2-}$} & $0-15$ & 0.0923 & 0.95 & 9.3 \\
\hline & & $15-60$ & 0.0015 & 0.98 & 1395.4 \\
\hline \multirow{7}{*}{ ANT } & \multirow{2}{*}{$\mathrm{Cr}$} & $0-15$ & 0.1791 & 0.77 & 9.3 \\
\hline & & $15-60$ & 0.0341 & 0.86 & 95.7 \\
\hline & \multirow{2}{*}{$\mathrm{SO}_{4}^{2-}$} & $0-15$ & 0.1739 & 0.99 & 18.0 \\
\hline & & $15-60$ & 0.0247 & 0.85 & 229.2 \\
\hline & \multirow{2}{*}{$\mathrm{HCO}_{3}^{-}$} & $0-15$ & 0.1356 & 0.92 & 20.1 \\
\hline & & $15-60$ & 0.0260 & 0.9 & 160.1 \\
\hline & $\mathrm{HPO}_{4}^{2-}$ & $0-60$ & 0.0261 & 0.95 & 52.6 \\
\hline \multirow{6}{*}{$\mathrm{BaP}$} & $\mathrm{Cl}^{4}$ & $0-15$ & 0.2487 & 0.83 & 18.8 \\
\hline & \multirow{2}{*}{$\mathrm{SO}_{4}^{2-}$} & $0-15$ & 0.1026 & 0.83 & 45.7 \\
\hline & & $15-60$ & 0.0247 & 0.85 & 219.4 \\
\hline & $\mathrm{HCO}_{3}^{-}$ & $0-60$ & 0.0723 & 0.92 & 27.7 \\
\hline & \multirow{2}{*}{$\mathrm{HPO}_{4}^{2-}$} & $0-15$ & 0.1146 & 0.73 & 14.3 \\
\hline & & $15-60$ & 0.0118 & 0.84 & 254.2 \\
\hline
\end{tabular}

in the presence of $\mathrm{Fe}^{3+}$ cations decreased only by $34 \%$ (Fig. 2c) and the removal rate of $\mathrm{BaP}$ did not exceed $20 \%$ (Fig. 2d). $\mathrm{Al}^{3+}$ ions had no impact on the adsorption rate of $\mathrm{BaP}$ but they contributed to the increase in the adsorption rate of ANT, which reached $97 \%$.

Additionally, it was determined that the presence of $\mathrm{Fe}^{3+}$ ions in the micropolutant solutions also decreases the efficiency of photochemical degradation of all investigated compounds. For example, the decomposition rate of DCF after 60 min of irradiation reached only $46 \%$ and for solutions without salts the removal degree of this compound exceeded $90 \%$ (Fig. 2a). Similar results indicating the inhibition of the process of decomposition of micropollutants by $\mathrm{Fe}^{3+}$ ions were obtained during the photocatalytically decomposition of pharmaceutical compounds such as carbamazepine and ibuprofen [Kudlek et al. 2016]. Also the presence of $\mathrm{Al}^{3+}$ lead to an decrease in the DCF and OP decomposition compared to saltfree solution. However, in the case of ANT oxidation, the $\mathrm{Al}^{3+}$ ions assisted the decomposition of the compound, especially in the initial time of UV exposure (Fig. 2c). The removal degree of ANT after 5 min of irradiation reached above $98 \%$, and for the solution without salt it only received $90 \%$. On the other hand, $\mathrm{Al}^{3+}$ ions after the 15th min of UV irradiation of ANT and BaP solution did not have a significant influence on the reaction course. The removal degree of those compound equalled to $99 \%$ as in case of the process conducted with no inorganic compounds.

Table 3 summarizes the calculated reaction rate constants and half-lives of investigated compounds determined during the photocatalysis of solutions containing selected cations. The compounds half-lives estimated up to $15 \mathrm{~min}$ of UV irradiation and after the 15th min of the photocatalysis process demonstrate the same relationship as in the case of conducting the process in the presence of anions. Only for the decomposition of DCF in the presence of $\mathrm{Al}^{3+}$ and $\mathrm{Fe}^{3+}$ the halflives in the first stage of the process were longer than these calculated after the 15th min of irradiation. For example, the half-live between the beginning of the process and the 15th min for the solution containing $\mathrm{Al}^{3+}$ was equal to $66 \mathrm{~min}$ and the half-live between the 15th and 60th min was not longer than $3.3 \mathrm{~min}$. 
a)

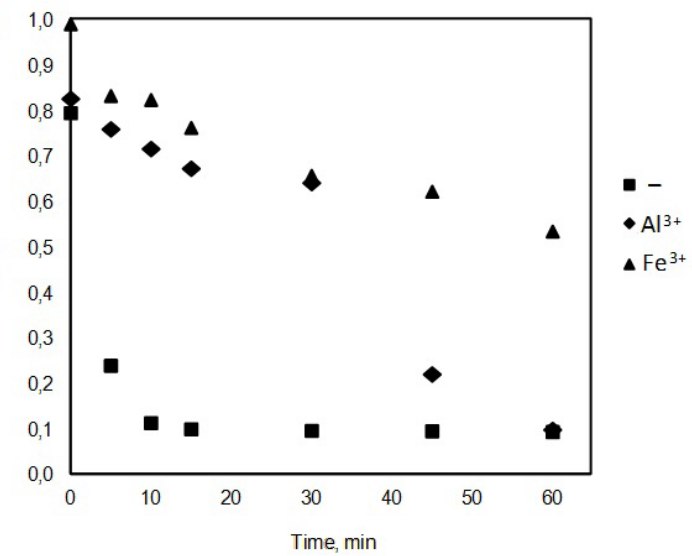

c)

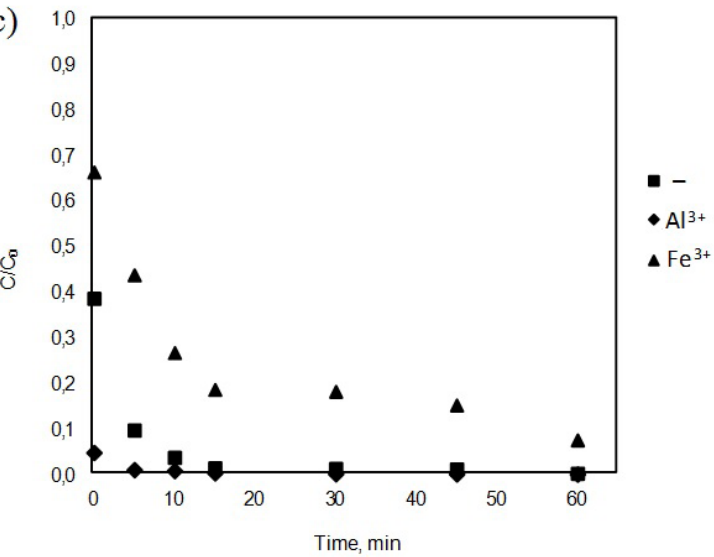

b)

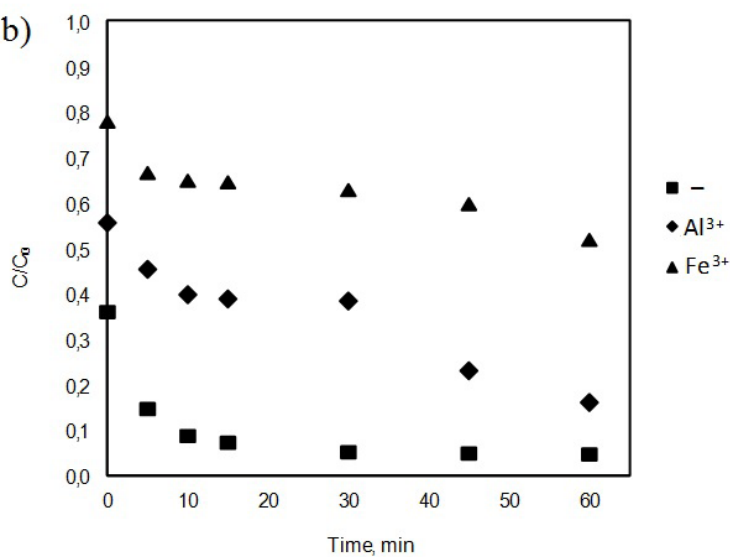

d)

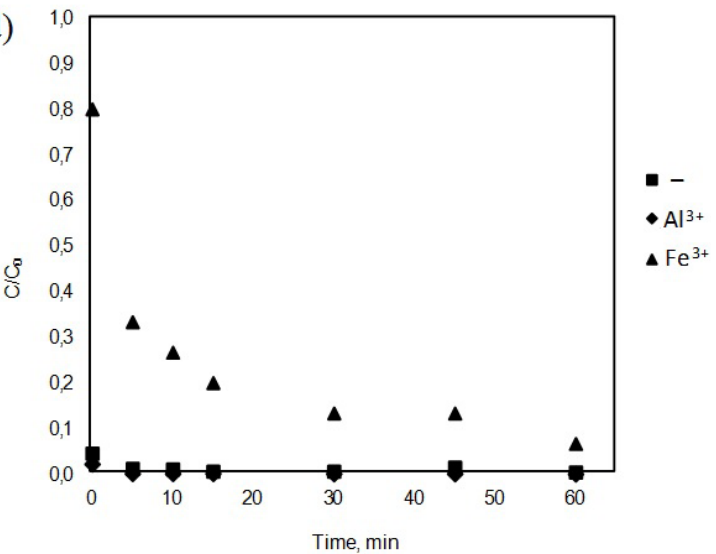

Figure 2. Influence of selected cations on the photocatalytic degradation of (a) DCF; (b) OP, (c) ANT and (d) $\mathrm{BaP}$ present in water solutions ( - water solution without inorganic compounds)

Table 3. Half-life of investigated micropollutants during heterogeneous photocatalysis of water solutions in the presence of selected cations

\begin{tabular}{|c|c|c|c|c|c|}
\hline Compound & lons & Reaction Time. $\min$ & Reaction Rate Constant $k . \mathrm{min}^{-1}$ & $R^{2}$ & Half-Life $t_{1 / 2} \cdot \min$ \\
\hline \multirow{6}{*}{ DCF } & \multirow{2}{*}{ - } & $0-15$ & 0.1395 & 0.89 & 8.4 \\
\hline & & $15-60$ & 0.0013 & 0.93 & 2288.8 \\
\hline & \multirow{2}{*}{$\mathrm{Al}^{2+}$} & $0-15$ & 0.0135 & 0.99 & 66.0 \\
\hline & & $15-60$ & 0.0456 & 0.91 & 3.3 \\
\hline & \multirow{2}{*}{$\mathrm{Fe}^{2+}$} & $0-60$ & 0.0091 & 0.94 & 86.8 \\
\hline & & $0-15$ & 0.0118 & 0.73 & 83.4 \\
\hline \multirow{5}{*}{ OP } & \multirow{2}{*}{ - } & $0-10$ & 0.1403 & 0.98 & 12.6 \\
\hline & & $10-60$ & 0.0117 & 0.83 & 266.0 \\
\hline & \multirow{2}{*}{$\mathrm{Al}^{2+}$} & $0-15$ & 0.0240 & 0.9 & 55.0 \\
\hline & & $15-60$ & 0.0209 & 0.91 & 57.5 \\
\hline & $\mathrm{Fe}^{2+}$ & $15-60$ & 0.0047 & 0.88 & 219.7 \\
\hline \multirow{6}{*}{ ANT } & \multirow{2}{*}{ - } & $0-10$ & 0.2313 & 0.99 & 7.4 \\
\hline & & $10-60$ & 0.0373 & 0.80 & 103.1 \\
\hline & \multirow{2}{*}{$\mathrm{Al}^{2+}$} & $0-15$ & 0.1477 & 0.9 & 26.9 \\
\hline & & $15-60$ & 0.0235 & 0.95 & 249.1 \\
\hline & \multirow{2}{*}{$\mathrm{Fe}^{2+}$} & $0-15$ & 0.0858 & 0.99 & 12.9 \\
\hline & & $15-60$ & 0.0191 & 0.77 & 101.2 \\
\hline \multirow{6}{*}{$\mathrm{BaP}$} & \multirow[b]{2}{*}{ - } & $0-10$ & 0.1338 & 0.87 & 29.5 \\
\hline & & $10-60$ & 0.0215 & 0.91 & 231.4 \\
\hline & \multirow{2}{*}{$\mathrm{Al}^{2+}$} & $0-10$ & 0.3091 & 0.75 & 16.3 \\
\hline & & $10-45$ & 0.0231 & 0.84 & 319.3 \\
\hline & \multirow{2}{*}{$\mathrm{Fe}^{2+}$} & $0-15$ & 0.0876 & 0.9 & 12.5 \\
\hline & & $15-60$ & 0.0220 & 0.87 & 88.9 \\
\hline
\end{tabular}




\section{CONCLUSION}

It was demonstrated that inorganic compound can influence the efficiency of micropollutants' decomposition. The oxidation process strictly depends on the type of compound as well as on the adsorption degree on semiconductor surface and the time of UV irradiation. The presence of $\mathrm{Cl}^{-}, \mathrm{SO}_{4}^{2-}, \mathrm{HCO}_{3}^{-}$and $\mathrm{HPO}_{4}^{2-}$ ions in the tested micropollutants solution significantly decreased the adsorption degree of organic compounds on the $\mathrm{TiO}_{2}$ surface. Only in the case of ANT solution a beneficial effect of $\mathrm{SO}_{4}^{2-}$ and $\mathrm{HCO}_{3}^{-}$ions on the adsorption degree of the compound was reported.

The highest decrease in the compound concentration after $60 \mathrm{~min}$ of photocatalysis, which exceed $99 \%$, was observed for ANT and BaP in solutions containing $\mathrm{Cl}^{-}, \mathrm{SO}_{4}^{2-}$ and $\mathrm{HCO}_{3}^{-}$ions. The lowest removal rate was observed for DCF in the presence of $\mathrm{HCO}_{3}^{-}$anions. The presence of $\mathrm{Fe}^{3+}$ cations inhibited the reaction course of the compound decomposition in all tested micropollutant solutions. $\mathrm{Al}^{3+}$ affected the decrease of the process efficiency only for DCF and OP. In case of ANT the presence of $\mathrm{Al}^{3+}$ increased the decomposition of the compound, especially in the initial time of UV exposure.

The analysis of the kinetics of heterogeneous photocatalysis process showed a difference between the rapidity of organic compounds' decoposition during the first $15 \mathrm{~min}$ of the process and the and the rapidity of the decomposition reactions observed after $15 \mathrm{~min}$ of UV radiation. This fact indicates the generation of oxidation by-products of parent compounds, which were competitive decomposed during the photochemical process.

\section{Acknowledgements}

The paper has been prepared within the frame of the National Science Center project based on decision No. DEC-2013/11/B/ST8/04391.

\section{REFERENCES}

1. Augugliaro V., Bellardita M., Loddo V., Palmisano G., Palmisano L., Yurdaka S., 2012, Overview on oxidation mechanisms of organic compounds by $\mathrm{TiO}_{2}$ in heterogeneous photocatalysis. Journal of Photochemistry and Photobiology C: Photochemistry Reviews, 13, 224-245.

2. Bohdziewicz J., Dudziak M., Kamińska G., Kudlek E., 2016, Chromatographic determination and toxicological potential evaluation of selected micropollutants in aquatic environment - analytical problems. Desalination and Water Treatment, 57(3), 1361-1369.

3. Chládková B., Evgenidou E., Kvítek L., Panáček A., Zbořil R., Kovář P., Lambropoulou, D. 2015, Adsorption and photocatalysis of nanocrystalline $\mathrm{TiO}_{2}$ particles for Reactive Red 195 removal: Effect of humic acids, anions and scavengers. Environmental Science and Pollution Research, 22, 16514-16524.

4. Giannakis S., Gamarra Vives F.A., Grandjean D., Magnet A., de Alencastro L.F., Pulgarin C., 2015, Effect of advanced oxidation processes on the micropollutants and the effluent organic matter contained in municipal wastewater previously treated by three different secondary methods. Water Research, 84, 295-306.

5. Kudlek E., Dudziak M., Bohdziewicz J., 2016, Influence of inorganic ions and organic substances on the degradation of pharmaceutical compound in water matrix. Water, 8(11), 1-18.

6. Kudlek E., Dudziak M., Kamińska G., Bohdziewicz J., 2017, Kinetics of the photocatalytic degradation of selected organic micropollutants in the water environment. Inżynieria Ekologiczna, 18(2), 75-82. (in Polish)

7. Li H., Dong Z., Weng Q., Chang C.C., Liu B., 2015, Emerging pollutants - Part I: occurrence, fate and transport. Water Environment Research, 87(10), 1849-1872.

8. Moreira N.F.F., Sousa J.M., Macedo G., Ribeiro A.R., Barreiros L., Pedrosa M., Faria J.L., Pereira M.F.R., Castro-Silva S., Segundo M.A., Manaia C.M., Nunes O.C., Silva A.M.T., 2016, Photocatalytic ozonation of urban wastewater and surface water using immobilized $\mathrm{TiO}_{2}$ with LEDs: Micropollutants, antibiotic resistance genes and estrogenic activity, Water Research, 94, 10-22.

9. Morris L., Colombo V., Hassell K., Kellar C., Leahy P., Long S. M., Myers J.H., Pettigrove V., 2017, Municipal wastewater effluent licensing: A global perspective and recommendations for best practice. Science of The Total Environment, 580, 1327-1339.

10. Ternes T., Joss A., Oehlmann J., 2015, Occurrence, fate, removal and assessment of emerging contaminants in water in the water cycle (from wastewater to drinking water). Water Research, 72, 1-2.

11. Tijani J., Fatoba O., Petrik L.F., 2013, A Review of pharmaceuticals and endocrine-disrupting compounds: sources, effects, removal, and detections. Water Air and Soil Pollution, 224(11), 1-29.

12. Zhang J., Wang X., Wang J., Wang J., Ji Z., 2016, Effect of sulfate ions on the crystallization and photocatalytic activity of $\mathrm{TiO}_{2}$ /diatomite composite photocatalyst. Chemical Physics Letters, 643, 53-60. 